\title{
Severidade de doenças foliares e produtividade de genótipos de milho em resposta à adubação nitrogenada ${ }^{1}$
}

\author{
Gil Rodrigues dos Santos ${ }^{2}$, Francismar Rodrigues Gama ${ }^{3}$, Clebson Gomes Gonçalves 4 , \\ Artenisa Cerqueira Rodrigues ${ }^{5}$, Evelynne Urzedo Leão ${ }^{6}$, Carlos Henrique Cardon ${ }^{4}$, Aurenivia Bonifacio ${ }^{7}$
}

\begin{abstract}
RESUMO
As doenças foliares, principalmente, helmintosporiose (Bipolaris spp.), antracnose (Colletotrichum graminicola) e ferrugem (Puccinia spp.), podem ocasionar redução do rendimento da cultura do milho. Este estudo teve como objetivo avaliar a ocorrência e severidade de helmintosporiose, antracnose e ferrugem, bem como a produtividade de genótipos de milho, em resposta a doses crescentes de nitrogênio. Avaliou-se a severidade das doenças, utilizando-se escala de notas, em nove genótipos de milho (AG9040, AG7088, 30F35, 3F624, 1F583, 1F632, 1F557, 1F640 e ID219), submetidos a quatro doses de nitrogênio (67; 112; 157; e $\left.202 \mathrm{~kg} \mathrm{ha}^{-1}\right)$, em duas safras (2009/2010 e 2010/2011). Para determinar a produtividade, utilizou-se a massa dos grãos coletados. Os graus de severidade da helmintosporiose, da antracnose e da ferrugem variaram em resposta às doses de nitrogênio e, entre os genótipos de milho avaliados durante as duas safras, entretanto, não houve relação clara entre as doses de nitrogênio aplicadas e a ocorrência das doenças nas duas safras. A ferrugem foi detectada apenas durante a safra I. Apesar da severidade das doenças foliares, elas, de modo geral, não afetaram significativamente a produtividade dos genótipos de milho avaliados. Desses, o genótipo de milho AG7088 pode ser considerado o mais produtivo e o mais resistente às doenças avaliadas.
\end{abstract}

Palavras-chave: helmintosporiose, antracnose, ferrugem, Zea mays, nitrogênio.

\section{ABSTRACT}

\section{Severity of foliar diseases and genotype maize yield in response to nitrogen fertilization}

Leaf diseases, mainly, helmintosporiosis (Bipolaris spp.), anthracnose (Colletotrichum graminicola) and rust (Puccinia spp.), may cause reduction in maize yield. This study aimed to evaluate the occurrence and severity of helmintosporiosis, anthracnose and rust, as well as productivity of different genotypes of maize in response to increasing doses of nitrogen. Disease severity was evaluated using a score scale in nine maize genotypes (AG9040, AG7088, 30F35, 3F624, 1F583, 1F632, 1F557, 1F640 and ID219) subjected to four different nitrogen levels (67; 112; 157; and $\left.202 \mathrm{~kg} \mathrm{ha}^{-1}\right)$ in two cropping years (2009/2010 and 2010/2011). To determine the productivity, it was used the weight of collected grains. It was observe that the severity of helmintosporiosis, anthracnose and rust varied in response to nitrogen levels and between the genotypes evaluated during two cropping years, although there was no clear relationship

Recebido para publicação em 13/08/2012 e aprovado em 03/05/2013.

'Parte da dissertação de mestrado do segundo autor.

${ }^{2}$ Engenheiro-Agrônomo, Doutor. Departamento de Fitopatologia, Universidade Federal do Tocantins, Campus Universitário de Gurupi, Caixa Postal 66, 77402-970, Gurupi, Tocantins, Brasil. gilrsan@uft.edu.br (autor para correspondência).

${ }^{3}$ Engenheiro-Agrônomo, Mestre. Departamento de Fitopatologia, Universidade Federal do Tocantins, Campus Universitário de Gurupi, Caixa Postal 66, 77402-970, Gurupi, Tocantins, Brasil. frgama@gmail.com.

${ }^{4}$ Graduando em Agronomia. Universidade Federal do Tocantins, Campus Universitário de Gurupi, Caixa Postal 66, 77402-970, Gurupi, Tocantins, Brasil. goncalvescg.agro@hotmail.com

${ }^{5}$ Engenheira-Agrônoma, Doutora. Departamento de Fitopatologia, Universidade Federal do Tocantins, Campus Universitário de Gurupi, Caixa Postal 66, 77402-970, Gurupi, Tocantins, Brasil. artenisacerqueira@ hotmail.com (Bolsista de Pós-Doutorado PNPD/CAPES).

${ }^{6}$ Engenheira-Agrônoma, Mestre. Departamento de Fitopatologia, Universidade Federal do Tocantins, Campus Universitário de Gurupi, Caixa Postal 66, 77402-970, Gurupi, Tocantins, Brasil. evelynnegpi@ hotmail.com

${ }^{7}$ Bióloga, Doutora. Departamento de Ciências Agrárias e Tecnológicas, Universidade Federal do Tocantins, Campus Universitário de Gurupi, Caixa Postal 66, 77402-970, Gurupi, Tocantins, Brasil. bonifacio.a@live.com 
between the nitrogen levels applied and disease incidence in two cropping years. Rust was detect only during the cropping year I. Although the severity of foliar diseases, in general, these did not significantly affect the productivity of the maize genotypes evaluated. Of the evaluated genotypes, genotype AG7088 can be consider the most productive and the most resistant to the diseases evaluated.

Key words: helmintosporiosis, anthracnose, rust, Zea mays, nitrogen.

\section{INTRODUÇÃO}

O milho (Zea mays L.) encontra-se entre os principais cereais cultivados no mundo e é amplamente utilizado no Brasil. Sua capacidade de adaptação às diferentes condições ambientais e seu valor nutricional explicam que sejam, anualmente, cultivados, no Brasil, aproximadamente oito milhões de hectares, com produção média de 54 milhões de toneladas do grão (ABRAMILHO, 2011). Com a crescente necessidade de aumento da produtividade, torna-se necessária a busca por tecnologias que promovam maiores crescimento, rendimento e desenvolvimento vegetal, como o manejo adequado das adubações nitrogenadas (Queiroz et al., 2011).

O nitrogênio é o nutriente essencial mais exigido pelas plantas e responsável por diversas reações biológicas, sendo o seu manejo um dos mais complexos dentre os macronutrientes (Marschner, 1995; Fagan et al., 2007). O estado nutricional é componente primário para o controle de doenças e, desta forma, o equilíbrio nutricional do vegetal é considerado um dos principais fatores responsáveis por mecanismos de defesa frente aos fatores bióticos (Gomes et al., 2007). O desequilíbrio nutricional relacionado com o nitrogênio pode resultar em aumento da severidade de determinadas doenças (Tomazela, 2005; Huber \& Thompson, 2007; Lima et al., 2010).

As doenças foliares na cultura do milho são responsáveis por reduções de $40 \%$ na produtividade de grãos (Casa \& Reis, 2003). Esse impacto cresce a cada ano, especialmente em razão do incremento das áreas irrigadas e daquelas sob cultivo de safrinha, levando a maior sobrevivência dos patógenos em campo (Tomazela et al., 2006; Fantin \& Duarte, 2009). O manejo mais eficiente para o controle de doenças na cultura envolve várias medidas, como o uso de variedades resistentes, rotação de culturas, eliminação de plantas infestantes e controle químico. Além destes, o manejo adequado para o balanço nutricional e o plantio da cultura em época adequada evitam que os períodos críticos para a produção coincidam com as condições ambientais mais favoráveis ao desenvolvimento das doenças (Casela et al., 2006).
Dentre as principais doenças e seus respectivos agentes etiológicos de natureza fúngica do milho, destacamse a helmintosporiose (Bipolaris spp.), a antracnose (Colletotrichum graminicola) e a ferrugem (Puccinia spp.), que causam danos significativos às plantas, em decorrência do mau funcionamento e destruição dos tecidos fotossintéticos (Casela et al., 2006; Fantin \& Duarte, 2009; Lima et al., 2010). Isso se dá por causa do aumento do número de lesões e da área afetada por elas, que podem determinar a necrose e a morte prematura das folhas, limitando a interceptação da radiação solar e a translocação de fotossintatos necessários ao desenvolvimento de grãos (Casa et al., 2004; Tomazela et al., 2006).

Diante do exposto, objetivou-se, com este trabalho, avaliar a ocorrência e a severidade de helmintosporiose (Bipolaris spp.), antracnose (Colletotrichum graminicola) e ferrugem (Puccinia spp.), bem como, a produtividade de diferentes genótipos de milho, em resposta a doses crescentes de nitrogênio.

\section{MATERIAL E MÉTODOS}

Os experimentos foram conduzidos no campo experimental da Universidade Federal do Tocantins (UFT) Campus Universitário de Gurupi. O campo experimental está localizado nas coordenadas $11^{\circ} 43^{\prime} 45^{\prime \prime}$ S e 49 $04^{\circ} 07^{\prime \prime} \mathrm{W}$, altitude média de $280 \mathrm{~m}$; o clima é da classe B1wA’a (úmido com moderada deficiência hídrica), segundo Köppen. Os experimentos foram conduzidos em dois períodos: safra 2009/2010 (safra I), quando a temperatura variou de 25,2 a $37,2{ }^{\circ} \mathrm{C}$ e ocorreu, em média, $73 \%$ de umidade relativa do ar; safra 2010/2011 (safra II), com temperaturas variando de 22,4 a $38,2{ }^{\circ} \mathrm{C}$ e, em média, $54 \%$ de umidade relativa do ar. Os dados da precipitação registrada durante os dois períodos experimentais (Safras I e II) encontram-se na Figura 1.

O solo do campo experimental foi classificado como Latossolo Vermelho- Amarelo distrófico (Embrapa, 2006). O preparo do solo para os dois experimentos (safras I e II) foi realizado de forma convencional, com aração seguida de gradagem; a adubação de base com NPK foi de $400 \mathrm{~kg}$ $\mathrm{ha}^{-1}$ (5-25-15) e os sulcos para o plantio foram abertos com arado subsolador. A caracterização química da cama- 
da de 0-20 $\mathrm{cm}$ do solo apresentou os seguintes resultados: $\mathrm{pH}\left(\mathrm{H}_{2} \mathrm{O}\right)=5,72 ; \mathrm{MO}=3,69 \mathrm{dag} \mathrm{kg}^{-1} ; \mathrm{P}=3,7 \mathrm{mg} \mathrm{dm}^{-3}$; $\mathrm{K}=27,11 \mathrm{mg} \mathrm{dm}^{-3} ; \mathrm{Ca}=1,72 \mathrm{cmol} \mathrm{dm}^{-3} ; \mathrm{Mg}=0,53 \mathrm{cmol} \mathrm{dm}^{-3}$; $\mathrm{Al}=0,08 \mathrm{cmol} \mathrm{dm}^{-3} ; \mathrm{H}+\mathrm{Al}=2,9 \mathrm{cmol} \mathrm{dm}^{-3} ;$ areia $=69,5 \mathrm{dag}$ $\mathrm{kg}^{-1} ;$ silte $=4,77 \mathrm{dag} \mathrm{kg}^{-1}$ e argila $=25,76$ dag $\mathrm{kg}^{-1}$.

Nos dois períodos experimentais, safras I e II, foram utilizadas sementes de nove genótipos de milho AG9040, AG7088, 30F35, 3F624, 1F583, 1F632, 1F557, 1F640 e ID219. O semeio foi realizado, distribuindo-se oito sementes de milho por metro linear e, após as plantas apresentarem duas folhas completamente expandidas, realizou-se o desbaste, mantendo-se cinco plantas por metro linear. A parcela experimental constituiu-se de seis linhas, espaçadas de $70 \mathrm{~cm}$ de largura por $6 \mathrm{~m}$ de comprimento. Foi realizada a capina manual, para o controle das plantas daninhas e, para controlar a lagarta do cartucho, realizaram-se duas pulverizações com o inseticida Permetrina (Pounce 384 $\mathrm{CE} ; 150 \mathrm{~mL} \mathrm{ha}^{-1}$ ). Durante o período experimental, não foram realizadas aplicações de fungicidas. A implantação do experimento foi realizada aos 45 dias após o plantio, com a aplicação da adubação de cobertura com as diferentes doses de nitrogênio (67; 112; 157; e 202 kg de $\left.\mathrm{N} \mathrm{ha}^{-1}\right)$. A adubação foi realizada nas entrelinhas, a $20 \mathrm{~cm}$ de distância dos colmos das plantas de milho.

Aos 60 dias após o plantio, iniciou-se a avaliação da severidade das doenças helmintosporiose, antracnose e ferrugem, em intervalos de cinco dias, totalizando sete avaliações até a colheita do experimento. Utilizou-se a escala de notas de severidade, que varia de 0 a 9 (Santos et al., 2005), em que: $O$ - planta sadia; 1 - menos de $1 \%$ da área foliar afetada; 3 - entre 1 e 5\% da área foliar afetada; 5 entre 6 e $25 \%$ da área foliar afetada; 7 - entre 26 e $50 \%$ da folha afetada; 9 - mais que $50 \%$ da área foliar afetada. $\mathrm{Na}$ ocasião da colheita do experimento, determinou-se a produtividade de cada tratamento, com base na massa dos grãos coletados nas duas fileiras centrais da área experimental, eliminando-se um metro de cada lado da parcela, e os dados foram expressos em toneladas por hectare $\left(\mathrm{t} \mathrm{ha}^{-1}\right)$.

O delineamento experimental utilizado nas duas safras foi em blocos ao acaso, com quatro repetições, usandose esquema fatorial de nove genótipos de milho por 4 níveis de adubação. Os dados originais de severidade da doença foram transformados para $\sqrt{\mathrm{X}+1}$, visando a obter a homogeneidade de variância, que foi verificada pelo teste de Levene. Os resultados de severidade da doença e da produtividade foram submetidos à análise de variância em esquema fatorial (teste $\mathrm{F}, P<0,05$ ). Quando o teste $\mathrm{F}$ foi significativo, realizou-se o teste de Scott-Knott $(P<0,05)$, para os genótipos, e análise de regressão para avaliar o efeito da aplicação das diferentes doses de nitrogênio. Todas as análises descritas foram realizadas, utilizandose programa estatístico SISVAR (Ferreira, 2008).

\section{RESULTADOS E DISCUSSÃO}

\section{Severidade da helmintosporiose (Bipolaris spp.) em folhas de plantas de milho}

Houve interação significativa $(P<0,05)$ entre os genótipos de milho e as doses de nitrogênio aplicadas, para a severidade da helmintosporiose (Teste de Scott-

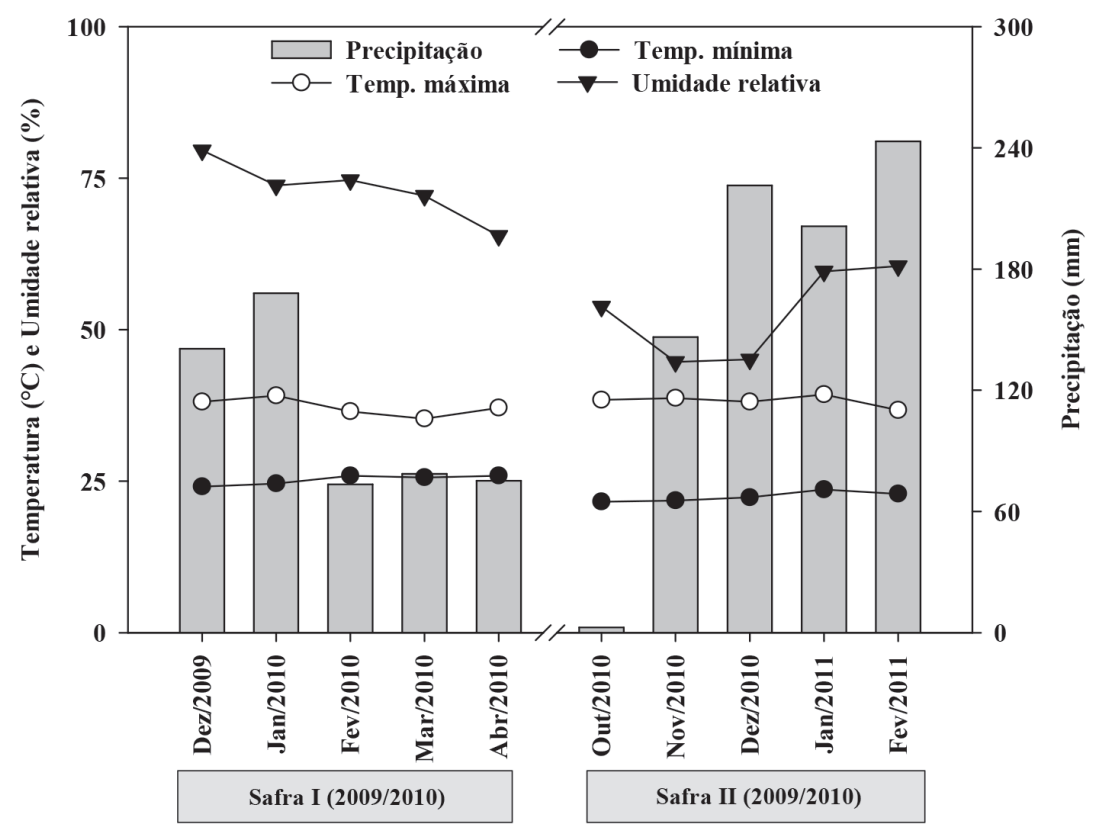

Figura 1. Dados climáticos (precipitação, temperatura e umidade relativa) do campo experimental da Universidade Federal do Tocantins (UFT) - Campus Universitário de Gurupi, obtidos durante o período de condução do experimento (Safra I - 2009/2010 e Safra II - 2010/2011). 
Knott; $P<0,05)$, avaliados durante as safras I e II (Tabela 1). Durante o período de condução dos experimentos, registraram-se temperatura média de $31,2^{\circ} \mathrm{C}$, na safra I, e de $30,3{ }^{\circ} \mathrm{C}$, na safra II, e umidade relativa de $73 \%$, na safra I, e de 54\%, na safra II (Figura 1), condições ambientais consideradas favoráveis ao aparecimento da helmintosporiose do milho. Segundo Modesto \& Fenille (2004), a helmintosporiose (Bipolaris spp.) manifesta-se em áreas com alta umidade relativa e temperaturas variando de 18 a $27{ }^{\circ} \mathrm{C}$ e desenvolve-se, inicialmente, nas folhas inferiores, progredindo para a parte superior da planta.

Os genótipos de milho 1F583 e 1F557 apresentaram maior severidade da helmintosporiose, com 26 a $50 \%$ da área foliar afetada (nota 7), na safra I, quando suplementadas com $112 \mathrm{~kg}$ de $\mathrm{N} \mathrm{ha}^{-1}$. O uso de adubação balanceada sem excesso de nitrogênio apresenta-se como um dos métodos de controle da helmintosporiose (Modesto \& Fenille, 2004). De fato, nas doses de nitrogênio mais elevadas, 157 e $202 \mathrm{~kg}$ de $\mathrm{N} \mathrm{ha}^{-1}$, houve maior severidade da helmintosporiose (nota 7) nos genótipos de milho ID219, 1F557, 1F583 e 30F35, na safra I (Tabela 1). Dentro da mesma espécie, os genótipos podem variar quanto à sus- ceptibilidade a determinada doença, como observado para os genótipos de milho 3F624 e AG7088, considerados como susceptível e resistente à helmintosporiose, respectivamente, independentemente das doses de nitrogênio aplicadas, na safra I (Tabela 1).

Na safra II, os genótipos de milho 1F640, 30F35 e AG7088 não apresentaram alterações significativas na severidade da helmintosporiose de milho (Teste de ScottKnott; $P<0,05$ ) em resposta à adubação nitrogenada (Tabela 1). Já os genótipos de milho ID219, 1F557, 1F583 e 3F624 apresentaram de 26 a 50\% da folha afetada (nota 7) pela helmintosporiose, quando suplementados com 157 e $202 \mathrm{~kg}$ de $\mathrm{N} \mathrm{ha}^{-1}$, enquanto o genótipo 1F632 apresentou a doença neste mesmo grau apenas quando suplementado

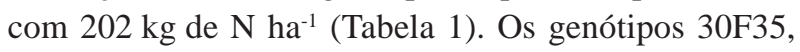
3F624, 1F583, 1F632, 1F557 e ID219 apresentaram entre 6e $25 \%$ da área foliar afetada (nota 5) pela helmintosporiose, quando suplementados com $67 \mathrm{~kg}$ de $\mathrm{N} \mathrm{ha}^{-1}$, na safra II. O genótipo AG7088 foi significativamente resistente à helmintosporiose, independentemente das doses de nitrogênio aplicadas (Teste de Scott-Knott; $P<0,05$ ), confirmando os resultados obtidos na safra I (Tabela 1).

Tabela 1. Severidade da helmintosporiose (Bipolaris spp.) em folhas de genótipos de milho suplementados com diferentes doses de nitrogênio nas safras I (2009/2010) e II (2010/2011)

\begin{tabular}{lcccccc}
\hline \multicolumn{7}{c}{ Safra I - 2009/2010 } \\
\hline Genótipos de nitrogênio $\left(\mathbf{k g ~ h a}^{-1}\right)$ \\
\hline ID219 & $\mathbf{6 7}$ & $\mathbf{1 1 2}$ & $\mathbf{1 5 7}$ & $\mathbf{2 0 2}$ & ${\text { Resposta ao } \mathbf{N}^{1}}^{\mathbf{R}^{\mathbf{2}}}$ \\
1F640 & $5,0 \mathrm{a}$ & $5,0 \mathrm{a}$ & $7,0 \mathrm{a}$ & $7,0 \mathrm{a}$ & LIN & $0,85^{* *}$ \\
1F557 & $3,0 \mathrm{~b}$ & $3,0 \mathrm{~b}$ & $3,0 \mathrm{~b}$ & $3,0 \mathrm{~b}$ & - & $\mathrm{ns}$ \\
1F632 & $5,0 \mathrm{a}$ & $7,0 \mathrm{a}$ & $7,0 \mathrm{a}$ & $7,0 \mathrm{a}$ & POL & $0,87^{* *}$ \\
1F583 & $5,0 \mathrm{a}$ & $5,0 \mathrm{a}$ & $5,0 \mathrm{~b}$ & $5,0 \mathrm{~b}$ & - & $\mathrm{ns}$ \\
3F624 & $5,0 \mathrm{a}$ & $7,0 \mathrm{a}$ & $7,0 \mathrm{a}$ & $7,0 \mathrm{a}$ & POL & $0,87^{* *}$ \\
30F35 & $7,0 \mathrm{a}$ & $7,0 \mathrm{a}$ & $7,0 \mathrm{a}$ & $7,0 \mathrm{a}$ & - & $\mathrm{ns}$ \\
AG7088 & $3,0 \mathrm{~b}$ & $5,0 \mathrm{a}$ & $7,0 \mathrm{a}$ & $7,0 \mathrm{a}$ & POL & $0,99^{*}$ \\
AG9040 & $1,0 \mathrm{~b}$ & $1,0 \mathrm{~b}$ & $1,0 \mathrm{~b}$ & $1,0 \mathrm{~b}$ & - & $\mathrm{ns}$ \\
\hline
\end{tabular}

\begin{tabular}{lcccccc}
\hline \multicolumn{7}{c}{ Safra II - 2010/2011 } \\
\hline Genótipos & $\mathbf{6}$ & $\mathbf{1 0 2}$ & \\
\hline ID219 & $\mathbf{6 7}$ & $\mathbf{1 1 2}$ & $\mathbf{1 5 7}$ & $\mathbf{2 0 2}$ & ${\text { Resposta ao } \mathbf{N}^{\mathbf{1}}}^{\mathbf{R}^{\mathbf{2}}}$ \\
1F640 & $5,0 \mathrm{a}$ & $5,0 \mathrm{a}$ & $7,0 \mathrm{a}$ & $7,0 \mathrm{a}$ & LIN & $0,85^{* *}$ \\
1F557 & $3,0 \mathrm{~b}$ & $3,0 \mathrm{~b}$ & $3,0 \mathrm{~b}$ & $3,0 \mathrm{~b}$ & - & $\mathrm{ns}$ \\
1F632 & $5,0 \mathrm{a}$ & $5,0 \mathrm{a}$ & $7,0 \mathrm{a}$ & $7,0 \mathrm{a}$ & LIN & $0,84^{* *}$ \\
1F583 & $5,0 \mathrm{a}$ & $5,0 \mathrm{a}$ & $5,0 \mathrm{~b}$ & $7,0 \mathrm{a}$ & POL & $0,93^{*}$ \\
3F624 & $5,0 \mathrm{a}$ & $5,0 \mathrm{a}$ & $7,0 \mathrm{a}$ & $7,0 \mathrm{a}$ & LIN & $0,85^{* *}$ \\
30F35 & $5,0 \mathrm{a}$ & $5,0 \mathrm{a}$ & $7,0 \mathrm{a}$ & $7,0 \mathrm{a}$ & LIN & $0,85^{* *}$ \\
AG7088 & $5,0 \mathrm{a}$ & $5,0 \mathrm{a}$ & $5,0 \mathrm{~b}$ & $5,0 \mathrm{~b}$ & - & $\mathrm{ns}$ \\
AG9040 & $1,0 \mathrm{~b}$ & $1,0 \mathrm{~b}$ & $1,0 \mathrm{c}$ & $1,0 \mathrm{c}$ & - & $\mathrm{ns}$ \\
\hline
\end{tabular}

Médias seguidas pela mesma letra minúscula na coluna não diferem estatisticamente entre si pelo teste de Scott-Knott a 5\% de probabilidade. ${ }^{1}$ Tipo de ajuste da regressão: $\mathrm{LIN}=$ efeito linear; POL = efeito polinomial. $\mathrm{R}^{2}=*$ significativo a $1 \%$; **significativo a $5 \%$; ns $=$ não significativo. Escala de notas da severidade: (1) menos de 1\% da área foliar afetada; (3) 1-5\% da área foliar afetada; (5) 6-25\% da área foliar afetada; (7) 26-50\% da área foliar afetada; (9) mais de $50 \%$ da área foliar afetada. 


\section{Ocorrência de antracnose (Colletotrichum graminicola) em plantas de milho}

Houve interação significativa $(P<0,05)$ entre os genótipos de milho e as doses de nitrogênio aplicadas, quanto à severidade da antracnose, nas safras I e II (Tabela 2). O teste de Scott-Knott $(P<0,05)$ indicou aumento significativo da severidade da antracnose nas folhas dos genótipos 1F557, 1F632, 3F624, 30F35 e AG9040, em resposta ao incremento das doses de nitrogênio aplicadas, na safra I (Tabela 2). Os genótipos ,AG9040, 1F632 e 1F557 tiveram de 26 a $50 \%$ da folha afetada (nota 7) pela antracnose, quando suplementados com $202 \mathrm{~kg}$ de $\mathrm{N} \mathrm{ha}^{-1}$, na safra I. Segundo Gomes et al. (2007), plantas suplementadas com doses elevadas de nitrogênio apresentam incremento no desenvolvimento vegetativo e, consequentemente, maior severidade de doenças, por causa da maior disponibilidade de área foliar. Além disso, maior suprimento de nitrogênio leva ao aumento da concentração de aminoácidos e amidas no apoplasto e na superfície foliar (Malavolta, 2006; Huber \& Thompson, 2007). Esses compostos parecem estar relacionados com o desenvolvimento de conídios e, consequentemente, de doenças (Santos et al., 2003; Lima et al., 2010).
A adubação com baixas doses de nitrogênio durante o período de crescimento vegetativo pode reduzir dramaticamente a severidade da antracnose (Inguagiato et al., 2008). De fato, neste estudo, os genótipos AG9040, 30F35, 3F624 e 1F632 demonstraram menor severidade da antracnose, de 1 a $5 \%$ da área foliar afetada (nota 3), quando suplementados com a menor dose de nitrogênio (67 kg de $\mathrm{N} \mathrm{ha}^{-1}$ ), na safra I. Os genótipos AG7088 e ID219 apresentaram de 1 a $5 \%$ da área foliar afetada pela antracnose (nota 3 ), independentemente da dose de nitrogênio aplicada e, desta forma, podem ser considerados genótipos resistentes à antracnose, quanto aos resultados da safra I (Tabela 2).

Durante a safra II, a antracnose não afetou mais que $25 \%$ da área foliar das plantas avaliadas (Tabela 2) e essa resposta pode estar relacionada com as condições climáticas registradas durante a safra II, período em que houve maior precipitação pluviométrica e menor umidade relativa, em relação às verificadas na safra I. Piteira (2009) relatou correlação negativa entre a severidade da antracnose, em cajueiro, e o aumento da precipitação pluviométrica. Apesar de ser mais frequente em regiões de alta umidade, a antracnose é também relatada em áreas com baixa umi-

Tabela 2. Severidade da antracnose (Colletotrichum graminicola) em folhas de genótipos de milho suplementados com diferentes doses de nitrogênio nas safras I (2009/2010) e II (2010/2011)

\begin{tabular}{lcccccc}
\hline \multicolumn{7}{c}{ Safra I - 2009/2010 } \\
\hline Genótipos de nitrogênio $\left(\mathbf{k g ~ h a}^{-1}\right)$ \\
\hline ID219 & $\mathbf{6}$ & $\mathbf{1 1 2}$ & $\mathbf{1 5 7}$ & $\mathbf{2 0 2}$ & ${\text { Resposta ao } \mathbf{N}^{\mathbf{1}}}^{\mathbf{R}^{\mathbf{2}}}$ \\
1F640 & $3,0 \mathrm{~b}$ & $3,0 \mathrm{~b}$ & $3,0 \mathrm{~b}$ & $3,0 \mathrm{~b}$ & - & $\mathrm{ns}$ \\
1F557 & $5,0 \mathrm{a}$ & $5,0 \mathrm{a}$ & $5,0 \mathrm{a}$ & $5,0 \mathrm{~b}$ & - & $\mathrm{ns}$ \\
1F632 & $5,0 \mathrm{a}$ & $5,0 \mathrm{a}$ & $5,0 \mathrm{a}$ & $7,0 \mathrm{a}$ & POL & $0,94^{* *}$ \\
1F583 & $3,0 \mathrm{~b}$ & $5,0 \mathrm{a}$ & $7,0 \mathrm{a}$ & $7,0 \mathrm{a}$ & POL & $0,99^{*}$ \\
3F624 & $5,0 \mathrm{a}$ & $5,0 \mathrm{a}$ & $5,0 \mathrm{a}$ & $5,0 \mathrm{~b}$ & - & $\mathrm{ns}$ \\
30F35 & $3,0 \mathrm{~b}$ & $5,0 \mathrm{a}$ & $5,0 \mathrm{a}$ & $5,0 \mathrm{~b}$ & POL & $0,87^{* *}$ \\
AG7088 & $3,0 \mathrm{~b}$ & $3,0 \mathrm{~b}$ & $3,0 \mathrm{~b}$ & $5,0 \mathrm{~b}$ & POL & $0,94^{*}$ \\
AG9040 & $3,0 \mathrm{~b}$ & $3,0 \mathrm{a}$ & $3,0 \mathrm{~b}$ & $3,0 \mathrm{~b}$ & - & $\mathrm{ns}$ \\
\hline
\end{tabular}

Safra II - 2010/2011

\begin{tabular}{|c|c|c|c|c|c|c|}
\hline \multicolumn{7}{|c|}{ Doses de nitrogênio (kg ha-1) } \\
\hline Genótipos & 67 & 112 & 157 & 202 & Resposta ao $\mathbf{N}^{1}$ & $\mathbf{R}^{2}$ \\
\hline ID219 & $3,0 \mathrm{a}$ & $3,0 \mathrm{a}$ & $5,0 \mathrm{a}$ & $5,0 \mathrm{a}$ & LIN & $0,84^{* *}$ \\
\hline $1 \mathrm{~F} 640$ & $3,0 \mathrm{a}$ & $3,0 \mathrm{a}$ & $3,0 \mathrm{~b}$ & $3,0 \mathrm{~b}$ & - & ns \\
\hline 1F557 & $3,0 \mathrm{a}$ & $3,0 \mathrm{a}$ & $5,0 \mathrm{a}$ & $5,0 \mathrm{a}$ & LIN & $0,84^{* *}$ \\
\hline $1 \mathrm{~F} 632$ & $3,0 \mathrm{a}$ & $3,0 \mathrm{a}$ & $5,0 \mathrm{a}$ & $5,0 \mathrm{a}$ & LIN & $0,84^{* *}$ \\
\hline $1 F 583$ & $3,0 \mathrm{a}$ & $3,0 \mathrm{a}$ & $5,0 \mathrm{a}$ & $5,0 \mathrm{a}$ & LIN & $0,84^{* *}$ \\
\hline $3 \mathrm{~F} 624$ & $3,0 \mathrm{a}$ & $3,0 \mathrm{a}$ & $3,0 \mathrm{~b}$ & $5,0 \mathrm{a}$ & POL & $0,94^{* *}$ \\
\hline $30 F 35$ & $3,0 \mathrm{a}$ & $3,0 \mathrm{a}$ & $3,0 \mathrm{~b}$ & $5,0 \mathrm{a}$ & POL & $0,94^{* *}$ \\
\hline AG7088 & $1,0 \mathrm{~b}$ & $1,0 \mathrm{~b}$ & $1,0 \mathrm{~b}$ & $1,0 \mathrm{~b}$ & - & ns \\
\hline AG9040 & $3,0 \mathrm{a}$ & $3,0 \mathrm{a}$ & $3,0 \mathrm{~b}$ & $3,0 \mathrm{~b}$ & - & ns \\
\hline
\end{tabular}

Médias seguidas pela mesma letra minúscula na coluna não diferem estatisticamente entre si pelo teste de Scott-Knott a 5\% de probabilidade.

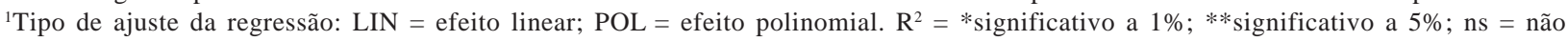
significativo. Escala de notas da severidade: (1) menos de 1\% da área foliar afetada; (3) 1-5\% da área foliar afetada; (5) 6-25\% da área foliar afetada; (7) 26-50\% da área foliar afetada; (9) mais de 50\% da área foliar afetada. 
dade relativa do ar, como o cerrado (Fischer et al., 2007). É provável que a incidência da doença nessas áreas seja menor, em decorrência da baixa umidade relativa do ar (Singh et al., 2001).

Foram registradas alterações significativas (Teste de Scott-Knott; $P<0,05)$ na severidade da antracnose, em genótipos de milho, em resposta à adubação nitrogenada, na safra II, exceto para os genótipos 1F640, AG7088 e AG9040 (Tabela 2). Houve severidade de 6 a 25\% da área foliar afetada (nota 5) pela antracnose, nos genótipos 30F35 e 3F624, apenas quando suplementados com 202 kg de $\mathrm{N} \mathrm{ha}^{-1}$. Os genótipos 1F583, 1F632, 1F557 e ID219 apresentaram entre 6 e $25 \%$ de área foliar afetada (nota 5) pela antracnose, quando suplementados com $157 \mathrm{~kg}$ de $\mathrm{N}$ ha $^{-1}$, na safra II. O crescimento e manutenção do vegetal requerem quantidades relativamente grandes de nitrogênio (Huber \& Thompson, 2007) e, nessas condições, pode ocorrer aumento da susceptibilidade das espécies vegetais a determinadas doenças, entre elas a antracnose (Smiley et al., 2005).

Além do manejo da adubação e do emprego de rotação de culturas, o uso de genótipos resistentes apresenta-se como método eficaz para o controle da antracnose, tanto na fase de podridão de colmo, quanto na fase foliar da doença (Coêlho et al., 2001). Dentre os genótipos avaliados, AG7088 apresentou menos de $1 \%$ da área foliar afetada (nota 1) pela antracnose, independentemente do nível de adubação nitrogenada utilizado, podendo, desta forma, ser considerado o genótipo de milho mais resistente à antracnose, durante a safra II (Tabela 2). Esse resultado pode ser explorado em trabalhos de melhoramento, de modo a se obter um genótipo com resistência à antracnose e alta produtividade de grãos.

\section{Ocorrência de ferrugem (Puccinia spp.) em plantas de milho}

Houve interação significativa $(P<0,05)$ entre os genótipos de milho e as doses de nitrogênio aplicadas, quanto à severidade da ferrugem, na safra I, enquanto, na safra II, não houve registro da ferrugem nas folhas dos genótipos avaliados (Tabela 3). É possível que a não incidência da ferrugem, durante a safra II, esteja relacionada com a condição climática do período, em que se registrou umidade relativa média de 54\% (Figura 1). De acordo com Kimati et al. (2005), a menor umidade relativa desfavorece o progresso da ferrugem. A ferrugem é uma doença predominante em áreas tropicais e subtropicais do mundo, áreas de elevada umidade, e é considerada uma das principais doenças incidentes em espécies agronomicamente importantes, como o milho (Fantin \& Duarte, 2009; Alves $\&$ Del Ponte, 2011).

O uso de variedades resistentes, a aplicação da rotação de culturas, a eliminação de plantas infestantes e o controle químico com fungicidas fazem parte de estratégias para o eficiente controle de doenças na cultura do milho (Machado \& Cassetari Neto, 2007). Neste estudo, os genótipos AG9040, 1F632 e 1F640 apresentaram severidade de 6 e $25 \%$ de área foliar afetada (nota 5) pela ferrugem, quando suplementados com $67 \mathrm{~kg}^{\mathrm{de}} \mathrm{N} \mathrm{ha}^{-1}$ e, com $202 \mathrm{~kg}$ de $\mathrm{N} \mathrm{ha}^{-1}$, os graus de severidade da doença atingiram de 26 a 50\% da área foliar (nota 7) dessas plantas (Tabela 3). Essa resposta pode indicar maior susceptibilidade desses genótipos à ferrugem.

A suplementação de plantas de milho com elevadas doses de nitrogênio pode ocasionar aumento da severidade da ferrugem (Tomazela et al., 2006). Entretanto, nos genótipos 1F583, 1F557 e ID219 registrou-se menos de $1 \%$ da área foliar afetada (nota 1) pela ferrugem, nas doses de 67, 112 e $157 \mathrm{~kg}$ de $\mathrm{N} \mathrm{ha}^{-1}$, enquanto, para o genótipo AG7088 esse resultado foi registrado em todas as doses de nitrogênio utilizadas (Tabela 3). Existem genótipos de milho com excelente resistência às doenças (Duarte et al., 2009) e este deve ser o caso do genótipo AG7088, que apresentou maior resistência à ferrugem, independentemente do nível de adubação nitrogenada aplicada.

\section{Produtividade de plantas de milho}

De modo geral, as doenças foliares avaliadas não afetaram significativamente a produtividade dos genótipos avaliados (Figura 2 e 3). Os genótipos ID219 e 1F640 apresentaram maior produtividade, na safra I, com $202 \mathrm{~kg}$ de $\mathrm{N} \mathrm{ha}^{-1}$, embora tenham apresentado mais de $25 \%$ da área foliar afetada pela ferrugem, além da ocorrência de helmintosporiose e antracnose. O genótipo de milho 1F640 apresentou incremento na linear na produtividade $\left(\mathrm{R}^{2}=\right.$ 0,808); entretanto, não foi responsivo ao nitrogênio, na safra II $\left(\mathrm{R}^{2}=0,021\right)$ e, diante disso, optou-se por não mostrar o gráfico da regressão junto com os dos demais genótipos. Em plantas de arroz de terras altas, observouse aumento na severidade de doenças e na produtividade, em resposta ao incremento das doses de nitrogênio (Cornélio et al., 2007). É provável que a resposta encontrada neste estudo justifique-se pelo fato de as doenças registradas ocorrerem ao final do ciclo da cultura, quando os grãos já estão formados.

O genótipo 1F557, quando suplementado com 67 e $112 \mathrm{~kg}$ de $\mathrm{N} \mathrm{ha}^{-1}$, apresentou menos de $1 \%$ da área foliar afetada pela ferrugem, associada com incidências de helmintosporiose e antracnose em maior grau (notas 5 e 7), na safra I, entretanto, registrou-se, para esse genótipo, maior produtividade, em comparação com a dos demais genótipos avaliados. Ainda na safra I, registrou-se maior produtividade para o genótipo 3F624, quando suplemen-

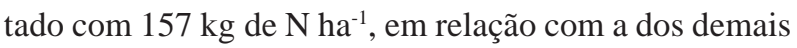
tratamentos (Figura 3A e 3B). De acordo com Gross et al. 
Tabela 3. Severidade da ferrugem (Puccinia spp.) em folhas de genótipos de milho suplementados com diferentes doses de nitrogênio na safra I (2009/2010)

\begin{tabular}{|c|c|c|c|c|c|c|}
\hline \multicolumn{7}{|c|}{ Safra I - 2009/2010 } \\
\hline \multicolumn{7}{|c|}{ Doses de nitrogênio (kg ha $\left.{ }^{-1}\right)$} \\
\hline Genótipos & 67 & 112 & 157 & 202 & Resposta ao $\mathbf{N}^{1}$ & $\mathbf{R}^{2}$ \\
\hline ID219 & $1,0 \mathrm{~b}$ & $1,0 \mathrm{~b}$ & $1,0 \mathrm{~b}$ & $5,0 \mathrm{a}$ & POL & $0,93^{* *}$ \\
\hline $1 \mathrm{~F} 640$ & $5,0 \mathrm{a}$ & $5,0 \mathrm{a}$ & $5,0 \mathrm{a}$ & $7,0 \mathrm{a}$ & POL & $0,93^{* *}$ \\
\hline 1F557 & $1,0 \mathrm{~b}$ & $1,0 \mathrm{~b}$ & $1,0 \mathrm{~b}$ & $3,0 \mathrm{~b}$ & POL & $0,93^{* *}$ \\
\hline 1F632 & $5,0 \mathrm{a}$ & $5,0 \mathrm{a}$ & $5,0 \mathrm{a}$ & $7,0 \mathrm{a}$ & POL & $0,93^{* *}$ \\
\hline 1F583 & $1,0 \mathrm{~b}$ & $1,0 \mathrm{~b}$ & $1,0 \mathrm{~b}$ & $3,0 \mathrm{~b}$ & POL & $0,93^{* *}$ \\
\hline $3 \mathrm{~F} 624$ & $3,0 \mathrm{a}$ & $3,0 \mathrm{a}$ & $3,0 \mathrm{a}$ & $3,0 \mathrm{~b}$ & ns & - \\
\hline $30 F 35$ & $3,0 \mathrm{a}$ & $3,0 \mathrm{a}$ & $3,0 \mathrm{a}$ & $5,0 \mathrm{~b}$ & POL & $0,93^{* *}$ \\
\hline AG7088 & $1,0 \mathrm{~b}$ & $1,0 \mathrm{~b}$ & $1,0 \mathrm{~b}$ & $1,0 \mathrm{~b}$ & $\mathrm{~ns}$ & - \\
\hline AG9040 & $5,0 \mathrm{a}$ & $5,0 \mathrm{a}$ & $5,0 \mathrm{a}$ & $7,0 \mathrm{a}$ & POL & $0,93^{* *}$ \\
\hline
\end{tabular}

Médias seguidas pela mesma letra minúscula na coluna não diferem estatisticamente entre si pelo teste de Scott-Knott a 5\% de probabilidade. ${ }^{1}$ Tipo de ajuste da regressão: $\mathrm{POL}=$ efeito polinomial; $\mathrm{R}^{2}=*$ significativo a $1 \%$; **significativo a $5 \%$; ns = não significativo. Escala de notas da severidade: (1) menos de 1\% da área foliar afetada; (3) 1-5\% da área foliar afetada; (5) 6-25\% da área foliar afetada; (7) 26-50\% da área foliar afetada; (9) mais de $50 \%$ da área foliar afetada.

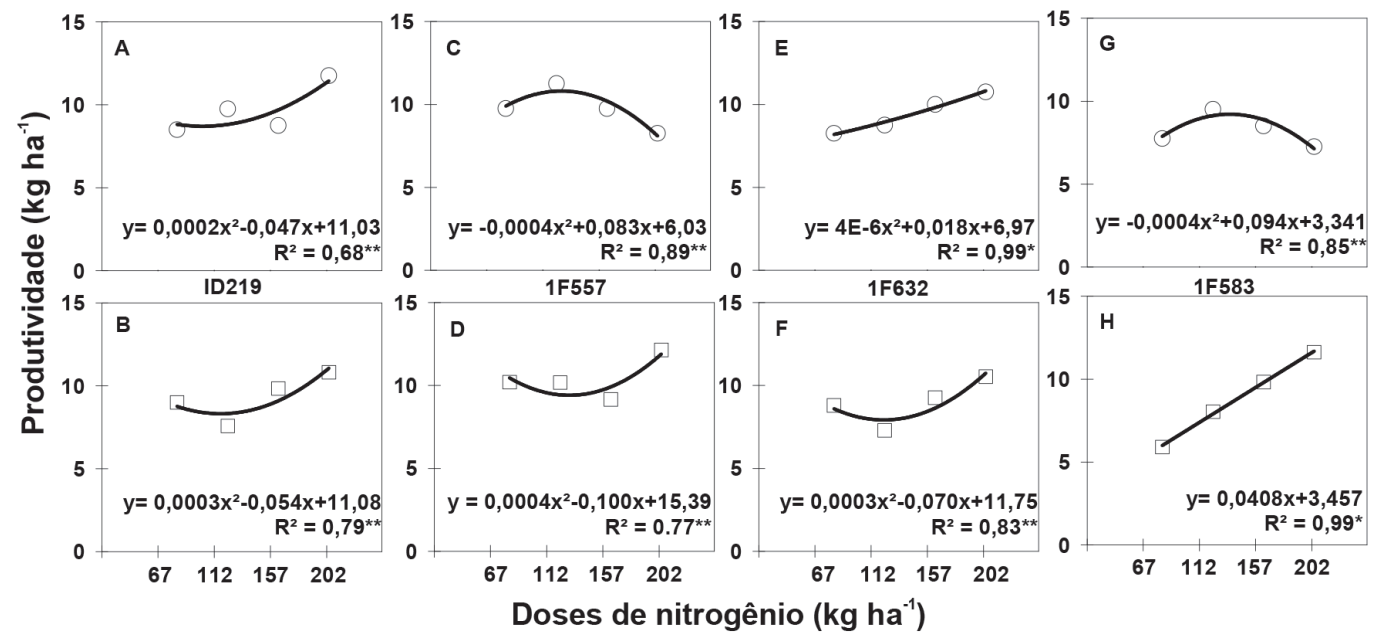

Figura 2. Produtividade média de genótipos de milho ID219, 1F557, 1F632 e 1F583 suplementados com diferentes doses de nitrogênio nas safras I-2009/2010 (A, C, E e G) e II-2010/2011 (B, D, F e H). Os símbolos * e ** indicam que o R² é significativo a 1 ou $5 \%$, respectivamente.
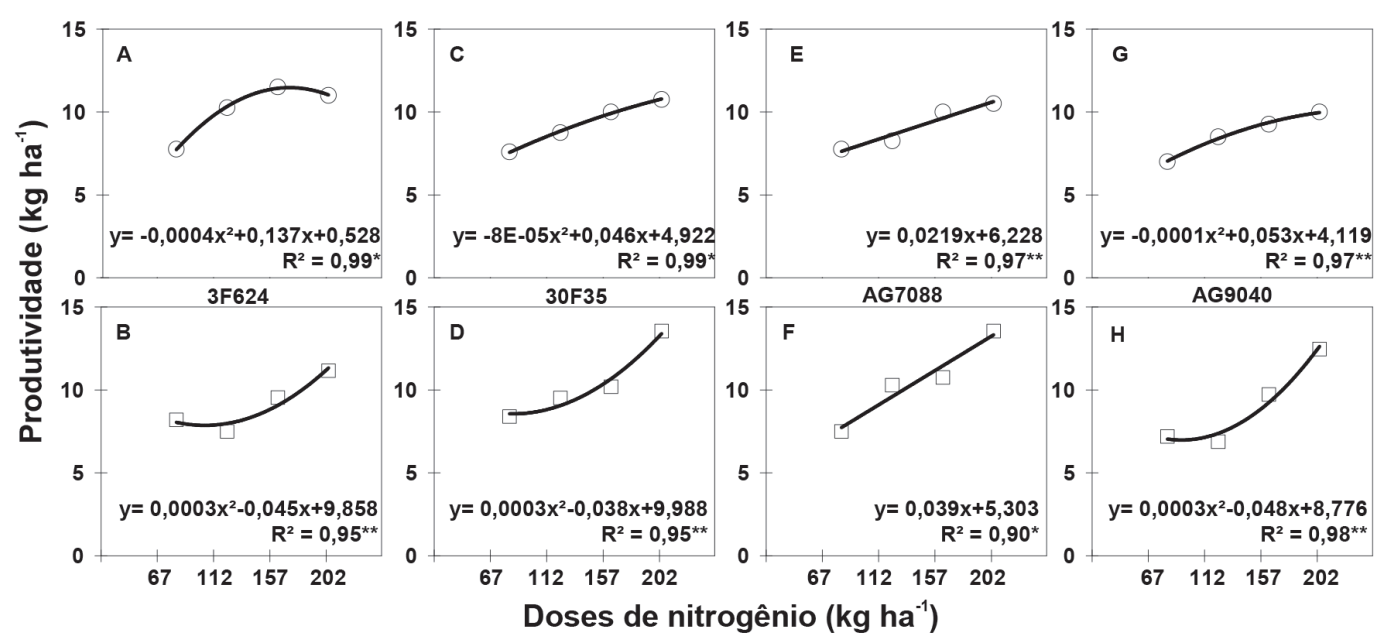

Figura 3. Produtividade média de genótipos de milho 3F624, 30F35, AG7088 e AG9040 suplementados com diferentes doses de nitrogênio nas safras I-2009/2010 (A, C, E e G) e II-2010/2011 (B, D, F e H). Os símbolos * e ** indicam que o R² é significativo a 1 ou $5 \%$, respectivamente. 
(2006), o nitrogênio é um dos nutrientes que induzem efeitos mais expressivos no aumento da produção de grãos na cultura do milho.

Embora a adequada adubação nitrogenada resulte em aumento da produtividade de inúmeras culturas, levando ao aumento da demanda por fertilizantes nitrogenados, o excesso de nitrogênio pode aumentar a susceptibilidade das plantas a determinadas doenças (Tomazela et al., 2006; Gomes et al., 2007). Segundo Malavolta (2006), vegetais com estado nutricional adequado apresentam inúmeras vantagens, com relação à resistência a determinadas doenças, comparados com plantas com estado de deficiência nutricional. Desta forma, o manejo adequado da nutrição das plantas apresenta-se como importante alternativa ao controle das doenças, em culturas agronomicamente importantes, como o milho (Duarte et al., 2009).

O genótipo AG9040 apresentou menor produtividade, quando suplementado com 67 e $112 \mathrm{~kg}$ de $\mathrm{N} \mathrm{ha}^{-1}$, em comparação com a dos demais tratamentos, na safra I (Figura 3G). Além disso, foram observados efeitos negativos na produtividade, quando os genótipos 1F557 e 1F583 foram

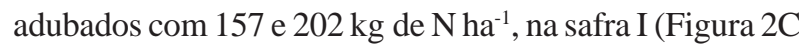
e $2 \mathrm{G})$. Apesar de induzir efeitos positivos nos vegetais, como observado, em milho, por vários autores (Coelho et al., 1992; Marschner, 1995; Ferreira et al., 2001; Ibrikci et al., 1998; Ceretta et al., 2002), doses elevadas de nitrogênio podem não induzir o aumento na produtividade e isto pode estar associado às características genéticas da cultura.

Durante a safra II, verificou-se menor produtividade dos genótipos 1F583, AG9040 e 1F557, quando suplementados com 67, 157 e $202 \mathrm{~kg}$ de $\mathrm{N} \mathrm{ha}^{-1}$, respectivamente (Figuras 2 e 3). Apenas o genótipo 1F640 não foi responsivo às doses crescentes de nitrogênio, aplicadas na safra II $\left(\mathrm{R}^{2}=0,021\right)$. Além disso, registrou-se maior produtividade para o genótipo 1F557, quando suplementado com $67 \mathrm{~kg}$ de $\mathrm{N} \mathrm{ha}^{-1}$. O genótipo AG7088 apresentou maior produtividade, quando suplementado com 112, 157 e $202 \mathrm{~kg}$ de $\mathrm{N} \mathrm{ha}^{-1} \mathrm{e}$, concomitantemente, severidade de menos de $1 \%$ de área foliar afetada, tanto pela antracnose como pela helmintosporiose, na safra II. Desta forma, o genótipo AG7088 pode ser considerado o mais resistente às doenças avaliadas e, ainda, o mais produtivo, em comparação com os demais genótipos estudados.

\section{CONCLUSÕES}

Apesar da incidência e severidade das doenças foliares, de modo geral, elas não afetaram significativamente a produtividade dos genótipos de milho. Entre os genótipos, o AG7088 pode ser considerado o mais produtivo e, ainda, o mais resistente às doenças avaliadas.

\section{REFERÊNCIAS}

ABRAMILHO - Associação Brasileira dos produtores de milho (2011) Área para milho e soja deve crescer. Disponível em: <http://www.abramilho.org.br/noticias.php? cod=1601>. Acessado em: 16 de julho de 2012.

Alves RC \& Del Ponte EM (2011) Fitopatologia.net. Disponível em: <http://www6.ufrgs.br/agronomia/fitossan/fitopatologia/ ficha.php?id=16>. Acessado em: 30 de julho de 2011.

Casa RT \& Reis EM (2003) Doenças na cultura do milho. In: Fancelli AL \& Dourado Neto D (Eds.) Milho: estratégia de manejo para alta produtividade. Piracicaba, ESALQ/USP. p.0118.

Casa RT, Reis EM \& Blum MMC (2004) Quantificação de danos causados por doenças em milho. In: I Workshop de Epidemiologia de Doenças de Plantas, Viçosa. Anais, UFV. p.0115.

Casela CR, Ferreira AS \& Pinto NFJA (2006) Doenças foliares. Disponível em: <http://sistemasdeproducao.cnptia.embrapa.br/ FontesHTML/Milho/CultivodoMilho/dfoliares.htm>. Acessado em: 16 de outubro de 2009

Ceretta CB, Basso CJ, Herbes MG, Poletto N \& Silveira MJ (2002) Produção e decomposição de fitomassa de plantas invernais de cobertura de solo e milho sob diferentes manejos da adubação nitrogenada. Ciência Rural, 32:49-54.

Coelho AM, França GC, Bahia AFC \& Guedes GA (1992) Doses e métodos de aplicação de fertilizantes nitrogenados na cultura do milho sob irrigação. Revista Brasileira de Ciência do Solo, 16:61-67.

Coêlho RMS, Silva HP, Brunelli KR \& Camargo LEA (2001) Controle monogênico da antracnose foliar em milho. Fitopatologia Brasileira, 26:640-643.

Cornélio VMO, Reis MS, Soares AA, Soares PC \& Oliveira JA (2007) Efeito de doses e épocas de aplicação de nitrogênio na incidência de doenças, produção e qualidade sanitária das sementes de arroz. Ciência e Agrotecnologia, 31:47-52.

Duarte RP, Juliatti FC \& Freitas PT (2009) Eficácia de diferentes fungicidas na cultura do milho. Bioscience Journal, 25:101-111.

Embrapa - Empresa Brasileira de Pesquisa Agropecuária (2006) Centro Nacional de Pesquisa de Solos. Sistema brasileiro de classificação de solos. $2^{\mathrm{a}}$ ed. Rio de Janeiro, Embrapa. 306p.

Fagan EB, Medeiros SP, Manfron PA, Casaroli D, Simon J, Dourado Neto D, Van Lier Q, Santos O \& Müller L (2007) Physiology of biologic fixation nitrogen in soybean - a review. Revista da FZVA, 14:89-106.

Fantin GM \& Duarte AP (2009) Manejo de doenças na cultura do milho safrinha. Campinas, Instituto Agronômico. p.16-19.

Ferreira ACB, Araújo GAA, Pereira PRG \& Cardoso AA (2001) Características agronômicas e nutricionais do milho adubado com nitrogênio, molibdênio e zinco. Scientia Agricola, 58:131138.

Ferreira DF (2008) SISVAR: um programa para análises e ensino de estatística. Revista Symposium, 6:36-41.

Fischer IH, Arruda MC, Almeida AM, Garcia MJM, Jeronimo EM, Pinoti RN \& Bertani RNA (2007) Doenças e características físicas e químicas pós-colheita em maracujá-amarelo de cultivo convencional e orgânico no centro-oeste paulista. Revista Brasileira de Fruticultura, 29:254-259.

Gomes RF, Silva AG, Assis RL \& Pires FR (2007) Efeito de doses e da época de aplicação de nitrogênio nos caracteres agronômicos da cultura do milho sob plantio direto. Revista Brasileira de Ciências do Solo, 31:931-938. 
Gross MR, Von Pinho RG \& Brito AH (2006) Adubação nitrogenada, densidade de semeadura e espaçamento entre fileiras na cultura do milho em sistema plantio direto. Ciência e Agrotecnologia, 30:387-393.

Huber DM \& Thompson LA (2007) Nitrogen and plant disease. In: Datnoff LE, Elmer WH \& Huber DM (Eds). Mineral nutrition and plant disease. St Paul, The American Phytopathological Society Press. p.31-44.

Ibrikci H, Ulger AC, Cakir B, Boyuk G \& Guzel N (1998) Modeling approach to nitrogen uptake by field-grown corn. Journal of Plant Nutrition, 21:1943-1954.

Inguagiato JC, Murphy JA \& Clarke BB (2008) Anthracnose severity on annual bluegrass influenced by nitrogen fertilization, growth regulators, and verticutting. Crop Science, 48:15951607.

Kimati H, Amorim L, Rezende JAM, Bergamin Filho A \& Camargo LEA (2005) Manual de fitopatologia: Doenças das plantas cultivadas. $4^{\mathrm{a}}$ ed. São Paulo, Agronômica Ceres. 663p.

Lima LM, Pozza EA, Torres HN, Pozza AAA, Salgado M \& Pfenning LH (2010) Relação nitrogênio/potássio com mancha de Phoma e nutrição de mudas de cafeeiro em solução nutritiva. Tropical Plant Pathology, 35:223-228.

Malavolta E (2006) Manual de nutrição mineral de plantas. São Paulo, Agronômica Ceres. 638p.

Marschner H (1995) Mineral nutrition of higher plants. $2^{\circ}$ ed. London. Academic Press. 889p.

Modesto JC \& Fenille RC (2004) Controle químico da helmintosporiose (Bipolaris incurvata) em coqueiro cultivar 'anão-verde' em condições de campo. Revista Brasileira de Fruticultura, 26:354-355.
Piteira, MCC (2009) Estudos da biodiversidade de isolados de Colletotrichum spp. que afectam a cultura do cajueiro por técnicas biomoleculares. Tese de Doutorado. Universidade de Évora, Évora. $136 \mathrm{p}$.

Queiroz AM, Souza CHE, Machado VJ, Lana RMQ, Korndorfer GH \& Silva AA (2011) Avaliação de diferentes fontes e doses de nitrogênio na adubação da cultura do milho (Zea mays L.). Revista Brasileira de Milho e Sorgo, 10:257-266.

Santos GR, Rangel PHN \& Câmara RK (2003) Avaliação da reação de genótipos de arroz irrigado a queima e mancha das bainhas em Tocantins. Bioscience Journal, 19:15-21.

Santos GR, Café-Filho AC, Leão FF, César M \& Fernandes LE (2005) Progresso do crestamento gomoso e perdas na cultura da melancia. Horticultura Brasileira, 23:228-232.

Singh R, Singh SB \& Singh PN (2001) Effect of environmental conditions on development of anthracnose of soybean. Annals of Plant Protection Sciences, 9:146-147.

Smiley RW, Dernoeden PH \& Clarke BB (2005) Compendium of turfgrass diseases. $3^{\mathrm{a}}$ ed. Saint Paul, American Pathological Society. $167 \mathrm{p}$.

Tomazela AL (2005) Adubação nitrogenada e de micronutrientes na produtividade e incidência de doenças foliares em milho. Dissertação de Mestrado. Escola Superior de Agricultura "Luiz de Queiroz", Piracicaba. 150p.

Tomazela AL, Favarin JL, Fancelli AL, Martin TN, Dourado Neto D \& Reis AR (2006) Doses de Nitrogênio e Fontes de Cu e Mn suplementar sobre a severidade da Ferrugem e Atributos morfológicos do milho. Revista Brasileira de Milho e Sorgo, 5:192-201. 